REVIEW ARTICLE

\title{
Traditional Uses and Variation in Curcumin Contentin Varieties of Curcuma-the Saffron of India
}

\section{B. Jyotirmayee, Gyanranjan Mahalik*}

Department of Botany, School of Applied Sciences, Centurion University of Technologyand Management, Odisha, India

Key words: Ethnobotanical, Pharmacological, Indian saffron, Curcumin

\section{Abstract}

Curcuma longa going by the name of turmeric, Indian saffron, golden spice, spice of life and yellow root gained out of a Latin term 'terra merita', meaning that admirable earth. The spice is commonly known in the kitchen used in traditional cultures and medicines for 6oooyears is now being used worldwide at the clinical and molecular level. There have been many studies published in the last few decades regarding the importance and uses of turmeric in Ayurvedic medicine, in modern medicine, in household uses for the different ailments remedy. Hence, signify its biological, clinical, pharmacological activities. This old age spice has now become an integral part of the vast research areas to develop new ways in the future. Curcumin, the polyphenol derived from turmeric, has been noticed by scientists and researchers worldwide as an antioxidant, anti-inflammatory, antibacterial and antiviral agent. This review emphasis on the importance and use of turmeric since ancient times to explore new areas of research which can be beneficial in today's generation. The objective of this article is to highlight its ethnobotanical significance, its different varieties, curcumin content and its uses in different areas. This provides a brief beneficial overview and shows its powerful medicinal activities in a wide area of research. Hence, concluded as the most beneficial medicinal plant worldwide.

diabetic foot ulcer, hepatic dysfunction, rheumatoid arthritis, and sinus infection (Rathod et al., 2019). Because Indian Haldi is of the richest quality, it has become the world's largest manufacturer and exporter. Erode, in Tamil $\mathrm{Nadu}$, is regarded as the world's largest producer of turmeric. As a result, it's also known as Yellow City, Turmeric City and Textile City (Prasad \& Aggarwal, 2011). Other leading states in India that grow turmeric include Telangana, Andhra Pradesh, Karnataka, Maharashtra, Assam, West Bengal, and Odisha (Choudhuri et al., 2018).

\section{Ethnobotany}

Ethnobotany is described as the study of the interactions between plants and people, as well as the indigenous plant uses in medicine, nutrition, and natural resource management (Behera et al., 2021). Ethnobotanists research the uses of plants in modern medicine and drug inquiry, such as food, shelter, clothing, and religious ceremonies. Turmeric is an aromatic plant with an orange-yellow rhizome, elliptic leaves measuring 40-6o x 13-15 cm, were used to treat bile duct diseases, atrophy, cough,

*Corresponding Author: gyanranjan.mahalik@cutm.ac.in 


\section{REVIEW ARTICLE}

acuminate, glabrous, long petiole, pedunculate spike, bracts, and coma colour, yellow flowers, and hairy ovary at the top. Turmeric has been utilized as a colouring substance for trade purposes in India since ancient times, according to ethnobotanical evidence (Prasad \& Aggarwal, 2011). Southeast Asia, China, Japan, Indochina, and the South Pacific Islands are all affected. This genus is used in a variety of dishes as a colour, taste, and flavour enhancer, as well as in the weaving industry as a dye that has been replaced by synthetic dyes (Velayudhan et al., 2012). It's frequently used to flavour or colour curry powders, mustards, butter, and cheeses, as well as a dye, drug, and cosmetic products, and religious ceremonies. It is the prime cash crop in Odisha's tribal districts. Kandhamal, Koraput, Mayurbhanj, Gajapati, and Ganjam areamong the districts. The Rhizome is used by traditional healers in the Semiliguda block of Koraput district to treat roundworm, skin infection, and snakebite. Roundworms are treated with turmeric and neem paste, and skin diseases are treated with turmeric and mustard oil paste. Traditional healers in the same district use another variety of turmeric, Curcuma montana (Sakuta, Haladikastura)(Revati \&Malathy, 2013). Curcuma montana rhizome is practised in the treatment of fever. Orally, a crushed rhizome is consumed. Turmeric's ethnobotanical uses include (Kumar et al., 2017).

1. Powdered rhizome paste is applied directly to skin diseases, and a thin uniform of paste is applied to beautify the hands and face.

2. Drinking a blend of powdered Haldi and milk, which acts as an expectorant, is used to treat cough.

3. Powdered rhizome is an anti-inflammatory, carminative, and blood purifier.

4. It is a common spice that is used to flavour and colour a variety of cuisines.

5. Haldi powder is utilized in many religious ceremonies, rituals, and rites.

\section{Varieties of Turmeric}

Turmeric grows best in a variety of tropical conditions at an altitude of 1500 meters. To thrive, it needs a mean temperature of 20 to 35 degrees Celsius and annual rainfall of 1500 to 2250 millimetres. It's grown in an irrigated environment. It can grow in a variety of soil types, including light black, sallow loamy, red, and clay loamy. However, it grows best in sandy, clay loamy, well-drained soils. The soil should be humus-rich and have a $\mathrm{pH}$ of 4.5-7.5 (Chaudhary et al., 2006).

In India, there are more than 30 varieties of turmeric, but not all of them are used in cooking. They are Erode, Suvarna, Krishna, Suguna, BSR-1, Sudarsana, Roma, IISR Prabha, IISR Prathibha, Suroma, Co-1, Sugandham, Rajendra Sonia, IISR Alleppey, Supreme, Rashmi, IISR Kedaram, Amalapuram, Armour, Ranga, Dindigam, RH-2, Kodur, RH10, Vontimitra, P317, GL Purm I and II (Rai et al., 2016). The 'Erode' variety is the most prominent and finest in India. The 'Krishna' variety of green turmeric yielded the
Ambient Science, 2022: Vol. 09(1); 06-12 DOI:10.21276/ambi.2022.09.1.rv01

most. Some of the well-known turmeric varieties include local Haldi, Allepey Finger, China scented variety, Thodopuza variety, and Red streaked variety. Kerala's 'Alleppey Finger' variety, Maharashtra Sangli, Rajapore variety, 'Nizamabad Bulb' cultivated in Andhra Pradesh and Telangana, and Duggirala cultivated in Andhra Pradesh is among India's principal turmeric varieties. Important varieties grown in Tamil Nadu include Erode local, Salem local, BSR-1, Sudarsana, PTS-10, Roma, and Suguna. Lakadong turmeric is a premium turmeric variety with the highest Curcumin content in the world. Curcumin levels are also high in Allepey Finger Turmeric. In Meghalaya, North East India, the Lakadong variety is raised in remote areas. Rajendra Sonia, Suroma, Rashmi, Roma, and Ranga are some of the best varieties of turmeric that are high in curcumin and have medicinal value. The most popular varieties used for skin rejuvenation and cosmetics are Kasturi and Keshari. The Lokhandi variety from Maharastra has bright hard rhizomes, whereas the Patna variety has a deep colour. The Duggirala of Andhra Pradesh has long, stout, smooth, and hard fingers. Other varieties found in Andhra Pradesh include Kasturi, Armoor, and Chaya (Varma \& Gopi, 2020).

Turmeric varieties such as Alllepey finger, Rajapuri, Madras, and Erode are exported. Madras and Allepey are the most prevalent variants among them. The Madras type is intense and bright, with $2 \%$ volatile oils and $2 \%$ Curcumin, while the Allepey type is an orange-yellow fleshy type with $3-5 \cdot 5 \%$ oils and $4-7 \%$ Curcumin. Turmeric powder, dry and fresh rhizome forms and oleoresin are all exported outside of India. Turmeric varieties such as 'Alleppey Finger, Erode, Rajapore, Sangli, and Nizamabad Bulb' are popular in the Middle East, the United Kingdom, the United States, and Japan (Angles et al., 2011).

The Kandhamal district in Odisha produces the most turmeric, followed by Koraput, Nayagarh, and Kheonjhar turmeric. It is cultivated by tribal tribes in remote areas of Odisha, accounting for about $21 \%$ of India's turmeric production. Odisha grows the turmeric varieties: Dughi, Jobedi, Katigia, Lakadong, Roma, Ranga, Rasmi, and Suroma (Babu et al., 2015).

An experiment was conducted on ten different turmeric varieties based on their vegetative growth. They noticed that the Pratibha, BSR-I, and Punjab Haldi genotypes outperform the control Rajendra Sonia (Sadanand et al., 2019).

Based on its aqueous and ethanolic extracts, the antioxidant properties and constituents of different varieties of turmeric were examined. The ethanolic extract of Chittagong's mura had the highest concentration of polyphenols, flavonoids, and ascorbic acid, whereas Chora had the highest yield, and the ethanolic extract had the highest antioxidant properties than the aqueous extract (Tanvir et al., 2017). Chaitanya, IISR Pratibha, IISR Prabha, 
IISR Allepy supreme, Chamarajanagar local turmeric varieties were evaluated in a study. The IISR Pratibha variety had the highest fresh and cured rhizome, followed by IISR Allepy supreme and IISR Prabha. The IISR Allepy supreme variety had the highest curing properties, followed by IISR Prabha and IISR Pratibha. The curcumin content of IISR Allepy supreme was the highest, followed by IISR Pratibha (Kumar et al., 2017).

The insects raised on Tekurpet had a high life span, life's duration rate, fertility rate, fecundity, intrinsic rate of natural increase, low death rate, mean production period, and doubling time (9.84), whereas the insects when reintroduced had a low life span, life's duration, fertility rate, fecundity, intrinsic rate of natural increase, high death rate, mean production period, and doubling time (Nischala \& Prasad, 2017).

The Ethiopian Dame variety had the highest total curcuminoids, polyphenol content, radical scavenging capacity, essential oil, and methanol extract content, while the $\mathrm{HT}_{3} / 2002$ variety had the lowest curcuminoids, essential oil, and methanol extract content. As a result, Dame is regarded as an effective biological perspective with strong antioxidant and antibacterial properties (Kebede et al., 2021). Maximum plant height, leaf length, leaf width, plant rhizome number, rhizome length, rhizome weight, fresh weight of rhizome per plant, dry weight of rhizome per plant, and curing percentage have all been observed in the Roma variety of Turmeric (Tiwari et al., 2018).

Turmeric comes in four different varieties. Krishna, Sudharsana, Narendra Haldi, and Pratibha have the least amount of leaf spot and produce the most. Krishna was moderately resistant (MR) and Pratibha, Sudharsana, and Narendra Haldi were tolerant (T) (Rathod et al., 2019).

\section{Some of the Varieties (Plotto, 2004)}

Roma: It thrives in hilly areas with plenty of rain and hydrated soil, and it blooms late in the season. It contains $6.1 \%$ curcumin, $13.2 \%$ oleoresin, and $4.2 \%$ essential oil.

Suroma: The rhizome is round and plump. In the field, it can tolerate leaf spots, leaf stains, and rhizome scale. Curcumin is 6.1 $\%$, oleoresin is $13.1 \%$, and essential oil is $4.2 \%$.

Ranga: It has a large, spindle-shaped rhizome. It thrives in lowlying areas and is best planted in the fall. It has a moderate level of resistance to leaf blotch and rhizome scales. Curcumin is $6.3 \%$, oleoresin is $13.5 \%$, and essential oil is $4.4 \%$.

Rasmi: The rhizomes are remarkably strong. Its growing season is suitable for rainfed, irrigated conditions, as well as early and late sown seasons. Curcumin is $6.4 \%$, oleoresin is $13.4 \%$, and essential oil is $4.4 \%$ in this blend.

Alleppey Finger: It has rhizomes that range in colour from deep yellow to orange. It contains $6.5 \%$ curcumin. It's used as food colouring.

Madras/Salem: It has a mustard yellow rhizome. It necessitates good soil conditions and the absence of cross-contamination. It contains $3.5 \%$ curcumin.
Rajapuri: The rhizome has a saffron yellow hue to it and contains 3.5 to $4 \%$ curcumin.

Duggirala: It has larger, high-quality rhizomes. Its growth necessitates the presence of heavy black soils. Curcumin concentration is $3 \%$.

\section{Various Species of Curcuma}

Genus Curcuma belongs to the Zingiberaceae family. It contains about 100 accepted species. It grows best in shaded areas having loose and sandy soil. The Curcuma genus is widespread among Southeast Asia, the Indian Subcontinent, Southern China, Northern Australia, and New Guinea. There are around 133 species of Curcuma identified worldwide out of that few varieties were found in different states of India(Table 1)(Sirirugsaet al., 2007).Curcuma amada, C. aromatic, C. angustifolia, and C. zedoaria are some of the most significant species in the genus Curcuma (Kaufman, 2016).

Table 1. Different Varieties of Turmeric

\begin{tabular}{lll}
\hline$\#$ & Varieties ofTurmeric & State \\
\hline 1. & Allepey Finger & Kerala \\
2. & Rajapore, Sangli & Maharastra \\
3. & Nizamabad Bulb & Andra Pradesh, Telangana \\
4. Duggirala & Andra Pradesh \\
5. & Erodelocal., Roma, PTS-10, & Tamil Nadu \\
6uguna, Sudarsana, BSR-1, Salem & \\
6. Lakadong & Meghalaya \\
7. Lokhandi & Maharastra \\
8. & Kasturi, Armoor, Chaya & Andra Pradesh \\
9. Dughi, Jobedi, Katigia, Roma, & Odisha \\
& Ranga, Rasmi, Suroma &
\end{tabular}

Curcuma amada (Mango ginger): it is a Zingiberaceae ginger family aromatic herb with rhizomatous characteristics. Turmeric and mango ginger have a close relationship. This herb can be found in many South-East Asian countries, including India, Bangladesh, and Sri Lanka. Mango ginger rhizome is used as an appetizer, alkaliser, stimulant, and balsamic in pickles, culinary preparations, and treatment. It possesses antioxidant activity, antimicrobial activity, anti-inflammatory activity, cytotoxicity, antiallergic activity, enterokinase inhibitory activity, analgesic activity, and more. It is utilized to treat sickness, dermatosis, chronic bronchitis, asthma, synchronous diaphragmatic flutter (SDF), and inflammation. The major compounds found in C.amada include starch, volatile oils, curcuminoids, phenolic acids, and terpenoids such as difurocumenonol, amadaldehyde, and amadannulen(Policegoudra et al., 2011).

Curcuma angustifolia (Wild arrowroot, narrowleaved turmeric): East Indian arrowroot, wild arrowroot, and narrow-leaved turmeric are some of the English names, while tikhur is the Hindi name. It is a member of the Zingiberaceae family. Northwestern, Central, and South India are its native habitats. It thrives in moist, cool 


\section{REVIEW ARTICLE}

environments (Sharma, 2012). This is used as a dietary aid in the treatment of gastrointestinal diseases, pain or inflamed mucus, and bronchitis. It has antimicrobial and antifungal properties (Doble et al., 2011). The study found that leaf oil compounds such as -eudesmol acetate (7.3\%), 14-hydroxycadinene $(18.6 \%)$, and curzerenone $(33.2 \%)$, as well as rhizome oil compounds such as camphor and germacrene (3.3\%) and curzerenone (72.6\%), are present. Camphor (4.2\%), palmitic acid (5.2\%), methyl eugenol (10.5\%), and xanthorrhizol isomer are among the major constituents of Central India rhizome oil (12.7\%). Southern Indian rhizome oil contains major constituents such as 1,8 cineole (4.8\%), curdione $(8.4 \%)$, isoborneol $(8.7 \%)$, camphor $(12.3 \%)$, and germacrene (12.8\%)(Srivastava et al., 2006).

Curcuma aromatic (Cochin turmeric, wild turmeric): it is a member of the Zingiberaceae family and is native to South Asia, the eastern Himalayas, and Tamil Nadu. It is used as a drug medicine for skin diseases, sprains, bruises, snake poison, epilepsy, autoimmune diseases, to improve complexion, cardiovascular and respiratory systems, cosmetic formulations, blood circulation promotion, blood stasis removal, wound healing, mosquito repellent, and anticancer herb in cancer treatment. It has antiinflammatory, anti-platelet, anti-tumor, antioxidant, antibacterial, anti-fungal, anti-diabetic, and anti-allergic properties (Sikha \& Harini, 2015). CA Snake poison uses rhizomes in particular. When combined with aromatics, astringents can help with injury, headaches, sprains, hiccoughs, respiratory problems, pertussis, achromoderma, and skin rashes (Rathaur et al., 2012). The anti-inflammatory properties of ethanol extracts are well known. CA contains Germacrone, a bioactive constituent with anti-tumour activity, according to many studies(Liu et al., 2014; Hu et al., 2011). CA extracts provide effective personal protection against mosquito bites (Pitasawat et al., 2003). An investigation of Curcuma aromatica rhizome essential oils in Japan and India discovered they were distinct from one another. Curdione, germacrene, 1, 8cineole, $(45,5 \mathrm{~S})$-germacrene-4, 5-epoxide, -elemene, and linalool are some of the key ingredients in Japanese tea. Curcumene, ar-curcumene, xanthorrhizol, germacrene, camphor, and curzerenone are components of Indian sample essential oil. C.aromatica can heal wounds in 9 to 11 days (Santhanam \& Nagarajan, 1990).

Curcuma zedoaria (Zedoary): it belongs to the Zingiberaceae family and is recognized as zedoary or white turmeric. These are prevalent in South Asia, Southeast Asia, and the state of Florida in the United States. The essential oil of dried rhizome contains 36 compounds, according to a study. Terpenes 17, alcohols 13, and ketones 6 were among the 36 compounds identified. Epicurzerenone (24.1\%) and Curzerene (10.4\%) have the highest and second-highest quantities (Mau et al., 2003). It has antimicrobial, antiamoebic, larvicidal, pain reliever, antinociception, hepatoportal, antiallergenic antiulcer, platelet-activating,
Ambient Science, 2022: Vol. 09(1); 06-12 DOI:10.21276/ambi.2022.09.1.rv01

antivenom, antifungal, anti-leukotriene, hemagglutinating, mutagen inhibiting, cytotoxic, anticancer, and antioxidant properties (Lobo et al., 2009).

\section{Uses of Turmeric}

Anti-leukotriene, antioxidant, anti-cancerous, anticarcinogenic, anticoagulation, antifertility, anti-diabetic, anti-microbial, anti-protozoal, anti-viral, anti-fibrotic, anti-venom, antiulcer, hypotensive, and hypocholesterolaemia are just a few of its properties. Curcuma longa is thought to be valuable to one's health. Enterococcus durans TP2 MH916769 was found to play a role in the immunity booster as a good probiotic candidate in the study (Sharma et al., 2021).

A studies revealed turmeric's healing benefits, which include promoting a balanced mood, wound healing, joint pain relief, blood sugar balancing, soothing irritated tissue, controlling cholesterol, treating tonic and acute allergies, treating asthma, eczema, acne, and psoriasis, curing digestive and eye disorders, liver disease, cancer, atherosclerosis, and osteoarthritis, and bacteria that causes osteoarthritis. It's known for being the most potent immunomodulatory (Yadav et al., 2017).

Curcumin is a potent antioxidant that helps to boost the body's antioxidant activity by blocking oxidative radicals. It also involved Curcumin in the induction of apoptosis and thus has anticarcinogenic properties. It also aids in the prevention of atherosclerosis, heart attacks, and strokes, as well as plaque build-up that causes artery blockage. It inhibits the growth of Helicobacter pylori CagA+ strains in vitro, as well as a variety of bacteria like Streptococcus, Lactobacillus, and others. It helps with indigestion by reducing bloating and gas symptoms. By calming the pores, it aids in the healing of wounds and the reduction of acne on the face. Obesity management, diabetes control, arthritis relief, and antifungal activity are among the other functions (Verma et al., 2018).

Turmeric has been used in food since ancient times and is thus considered an old spice. It was used as a dye and had many pharmaceutical uses in the nineteenth century, and it was regarded as a new spice (Cooksey, 2017). Turmeric rhizome is used to purify the blood, as a brain and heart tonic, and in the treatment of leucoderma, diabetes, hemorrhoids, and respiratory diseases such as chronic bronchitis and bronchial asthma, tumours, tuberculosis glands in the neck, spleen enlargement, leucorrhea, and gonorrhoeal discharge checking. It contains volatile oils and curcumin, both of which have anti-inflammatory properties. Its extract and essential oil inhibited many bacteria, parasites, and pathogenic fungi. Because of its antioxidant activity, it has hepatoprotective and renoprotective properties, as well as the ability to reduce the formation of pro-inflammatory cytokines. Because it contains curcumin and soluble water and fat extracts, it is used as a carcinogen and has strong antioxidant activity. It aids in the maintenance of low cholesterol and triglyceride 
levels, as well as lowering the susceptibility of low-density lipoprotein (LDL) to lipid peroxidation and platelet agglomeration. The constituent sodium curcuminate and p-tolymethylcarbinol have several protective effects on the gastrointestinal tract(Chanda \& Ramachandra, 2019).

Turmeric is a nutrient-dense natural food because it consists of an enormous amount of carbohydrates and fibre. It contains proteins, fats, vitamin C, pyridoxine, calcium, potassium, magnesium, and phosphorous. Turmeric inhibits the down-regulation of NF-B and its gene products, which is related to cancer cell persistence, proliferation, and metastasis, and thus has antitumor and anticancer properties. It fights colorectal, renal, hepatic, bone, lung, blood, and other cancers with anticancer properties. It inhibits the production of prostaglandin $\mathrm{E}_{2}$ in $\mathrm{HepG}_{2}$ cells and has antioxidant properties. Turmeric essential oil inhibits fungal growth, as well as the production of aflatoxins B1 and G1. Curcumin, in combination with epigallocatechin gallate (EGCG), has been shown to have increased antibacterial activity against Acinetobacter baumannii, multidrug-resistant bacteria. Acute myocardial infarction, cardiac arrest, cardiac hyperplasia, arteriosclerotic vascular disease (ASVD), cerebrovascular accident, diabetes mellitus, and other cardiovascular problems areall treated (Ahmad et al., 2020).

Curcumin, a polyphenol found in the Curcuma longa plant, is figured out to be the most effective biological component. Curcumin has anti-inflammatory properties, making it beneficial for rheumatologic conditions such as arthritis, dermatology, psoriasis, acne, itching, and skin wounds. Curcumin performs best in the processes of metastasis, angiogenesis, and cell death. It has an antioxidant effect because it lowers LDL blood levels and lowers the risk of atherosclerosis (Ahmad et al., 2020). Turmeric is extensively utilized in Asian cuisine and culture. It has been used for centuries to control disease prevention and cure by using it in traditional medicine, preclinical and clinical trials, and dermatology (Zdrojewicz et al., 2017). Turmeric has been used to treat and prevent a wide range of human-related disorders as a spice, food colorant, flavouring substance, cosmetics, and medicine or drug. It's a natural food colour that's too popular as a skincare product and a healthy food ingredient (Gopinath \& Karthikeyan, 2018; Ahmed et al., 2020).

Turmeric is a boon because it is used in a variety of therapeutic properties in our daily activities. It possesses antiseptic properties and is used as a disinfectant in burns and cuts. It promotes wound healing. It has antidiabetic, antiapoptotic, antiangiogenic, anti-inflammatory, and immunomodulatory properties because it regulates insulin levels, lowers blood cholesterol, strengthens the immune system, aids in the liver's detoxification and fat metabolism, and acts as a natural pain reliever in the treatment of arthritis. It's too used to prevent platelet aggregation, cancer cell metastasis, melanoma, and the risk of childhood leukaemia. It's also used as a colourant in pit-and-fissure sealants and dental plaque detection systems because it has anti-inflammatory properties that help with pain relief, gingivitis, and periodontitis. Its chemopreventive activity is demonstrated in premalignant lesions and conditions treated in the oral cavity. It has antioxidant and free radical properties that inhibit carcinogenesis, mutagenesis, oncogene expression, cell cycle regulation, apoptosis, tumorigenesis, metastasis, and precancerous lesions and conditions in the early stages. It is used as an antibacterial agent in the treatment of infected root canals. It is available, cost-effective, and can be used for a variety of biological activities (Kuwatada et al., 2017).

\section{Conclusion :}

Turmeric is a marvel to humanity because it contains a plethora of biological activities that benefit the modern world. Curcumin, the main active compound, and its constituents have a wide range of biological effects. Many experimental data showed significant evidence in favour of turmeric as a natural product in the treatment of various diseases causing no human toxicity. There is enough information about turmeric uses other than as a spice and medicinal uses, but more research is needed in the future to develop new products.

\section{Acknowledgements:}

I acknowledge the contributions of eminent authors whose works, ideas enriched this work. I gratefully like to thank my guide Dr. Gyanranjan Mahalik for his valuable suggestions in completing this review.

\section{References:}

Ahmad, R.S., Hussain, M.B., Sultan, M.T., Arshad, M.S., Waheed, M., Shariati, M.A., Plygun, S. \& Hashempur, M.H. (2020): Biochemistry, safety, pharmacological activities, and clinical applications of turmeric: A mechanistic review. EvidenceBased Complement. Alter. Med. Article ID 7656919.

Ahmed, M., Srivastava, U. \& Gupta, C. (2020): Turmeric: biological operations and medicinal applications, pp- 163172. In: Ethnopharmacological Investigation of Indian Spices. Pub. by: IGI Global.

Ahn, K. (2017): The worldwide trend of using botanical drugs and strategies for developing global drugs. BMB Reports. 50(3):111.

Angles, S., Sundar, A. \& Chinnadurai, M. (2011): Impact of globalization on production and export of turmeric in IndiaAn economic analysis. Agri. Econ Res. Rev., 24:301-308.

Babu, N., Shukla, A.K., Tripathi, P.C. \& Prusty, M. (2015): Traditional cultivation practices of turmeric in the tribal belt of Odisha. J. Eng. Comp. Appl. Sci., 4(2):52-57.

Behera, K., Mandal, U., Panda, M., Mohapatra, M., Mallick, S.K., Routray, S., Parida, S. \& Mahalik, G. (2021): Ethnobotany and Folk Medicines Used by the Local Healers of Bhadrak, Odisha, India. Egypt. J. Bot., 61(2):375-389.

Chanda, S. \& Ramachandra, T.V. (2019): Phytochemical and pharmacological importance of turmeric (Curcuma longa): a review. Res. Rev.:J. Pharmacol.,9(1):16-23.

Chaudhary, A.S., Sachan, S.K. \& Singh, R.L. (2006): Studies on 


\section{REVIEW ARTICLE}

varietal performance of turmeric (Curcuma longa L.). Indi.J. Crop. Sci.,1(1-2):189-190.

Choudhuri, P., Das, S. \& Sharangi, A.B. (2018): Organic spices, pp.177-204. In: Indian Spices. Pub. by: Springer Nature Switzerland AG. Part of Springer Nature.

Cooksey, C.J. (2017): Turmeric: old spice, new spice. Biotech Histochem., 92(5):309-314.

Doble, B., Dwivedi, S., Dubey, K. \& Joshi, H. (2011): Pharmacognostical and antimicrobial activity of leaf of Curcuma angustifolia Roxb. Internet J. Drug Discov. Herb Res., 1(2):46-49.

Gopinath, H. \& Karthikeyan, K. (2018): Turmeric: a condiment, cosmetic, and cure. India. J. Dermatol. Venereol. Leprol., $84(1): 16$.

Hu, B., Shen, K.P., An, H.M., Wu, Y. \& Du, Q. (2011): Aqueous extract of Curcuma aromatica induces apoptosis and G2/M arrest in human colon carcinoma LS-174-T cells independent of p53. Cancer Biother. Radiopharm., 26(1):97-104.

Jadhav, P. \& Jagadale, S. (2018): Herbal biomarkers in angiogenesis. J.Pharmacogn. Phytochem., 6:28-30.

Kaufman, S. (2016): Zingiber officinale (Ginger). In: Invasive Species Compendium. Pub. by: CABI, Wallingford UK.

Kebede, B.H., Forsido, S.F., Tola, Y.B. \& Astatkie, T. (2021): Free radical scavenging capacity, antibacterial activity, and essential oil composition of turmeric (Curcuma domestica) varieties grown in Ethiopia. Heliyon., 7 (2):eo6239.

Kumar, M.A., Yogesh, G.S., Navi, S.S., Naresh, N.T. \& Hanagi, C. (2017): Varietal Performance of Turmeric (Curcuma longa L.) in Chamarajanagar District of Karnataka. J. Krishi Vigyan., 6(1):217-220.

Kuwatada, J.S., Raja, M. \& Sood, P. (2017): Turmeric: a boon to oral health. Int.J. Oral Care Res., 5(3):338-341.

Liu, B., Gao, Y.Q., Wang, X.M., Wang, Y.C. \& Fu, L.Q. (2014): Germacrone inhibits the proliferation of glioma cells by promoting apoptosis and inducing cell cycle arrest. $\mathrm{Mol}$. Med. Rep., 10(2):1046-1050.

Lobo, R., Prabhu, K.S., Shirwaikar, A. \&Shirwaikar, A. (2009): Curcuma zedoaria Rosc (white turmeric): a review of its chemical, pharmacological and ethnomedicinal properties. J.Pharm. Pharmacol., 61(1):13-21.

Mau, J.L., Lai, E.Y., Wang, N.P., Chen, C.C., Chang, C.H. \& Chyau, C.C. (2003): Composition and antioxidant activity of the essential oil from Curcuma zedoaria. Food Chem., 82(4):583591.

Nischala, A. \& Prasad, K.H. (2017): Construction of life table parameters of the cigarette beetle, Lasioderma serricorne on different varieties of dry turmeric. L. Entomol. Zool. Stud., 5:118-124.

Pitasawat, B., Choochote, W., Tuetun, B., Tippawangkosol, P., Kanjanapothi, D., Jitpakdi, A. \& Riyong, D. (2003): Repellency of aromatic turmeric Curcuma aromatica under laboratory and field conditions. J. Vector Ecol., 28(2):234-240.

Plotto, A. (2004): Turmeric: Post-production Management. Pub. by: Food and Agriculture Organization of the United Nations (FAO), AGST.

Policegoudra, R.S., Aradhya, S.M. \& Singh, L. (2011): Mango ginger (Curcuma amada Roxb.)-A promising spice for phyto-
Ambient Science, 2022: Vol. 09(1); 06-12 DOI:10.21276/ambi.2022.09.1.rv01

chemicals and biological activities.J. Biosci., 36(4):739-748.

Prasad, S. \& Aggarwal, B.B. (2011): Turmeric, the Golden Spice: From Traditional Medicine to Modern Medicine. In: Benzie IFF, Wachtel-Galor S, (eds.) Herbal Medicine: Biomolecular and Clinical Aspects. 2nd edition. Pub. by: CRC Press/Taylor \& Francis, Boca Raton (FL)

Priyadarsini, K.I., Maity, D.K., Naik, G.H., Kumar, M.S., Unnikrishnan, M.K., Satav, J.G. \& Mohan, H. (2003): Role of phenolic $\mathrm{OH}$ and methylene hydrogen on the free radical reactions and antioxidant activity of curcumin. Free Radic. Biol. Med., 35(5):475-484.

Rai, S.K., Rai, K.K., Pandey, N., Kumari, A., Tripathi, D. \& Rai, S.P. (2016): Varietal performance of turmeric (Curcuma longa L.) with special reference to curcumin and essential oil content under climatic conditions of Indogangetic plains. Veg. Sci., 43(1):36-43.

Rathaur, P., Raja, W. \& Ramteke, P.W. (2012). Turmeric: The golden spice of life. Int. J. Pharm. Sci. Res., 3(7):1987-1994.

Rathod, R.R., Suryawanshi, A.P., Khandekar, R.G., Pethe, U.B. \& Gondhalekar, C.B. (2019): Varietal reactions of Turmeric towards leaf spot and rhizome rot disease in Konkan Region of Maharashtra, India. Int. J. Curr. Microbiol. App. Sci., 8(10):1735-1741.

Revathi, S. \& Malathy, N.S. (2013): Antibacterial activity of rhizome of Curcuma aromatica and partial purification of active compounds. India. J. Pharm. Sci., 75(6):732.

Sadanand, D., Misra, S., Ranjan, N.K., Kumar, A., Sengupta, S., Kumar, R. \& Nath, S. (2019): Evaluation of genetic parameters of different varieties of turmeric (Curcuma longa L.) under Ranchi condition. J. Pharmacogn. Phytochem., SP5:339-340.

Santhanam, G. \& Nagarajan, S. (1990): Wound healing activity of Curcuma aromatica and Piper betel. Fitoterapia., 61(5):458459.

Shankar, R., Tripathi, A.K. \& Kumar, A. (2015): Exploration, conservation, and cultivation of therapeutically important medicinal plants in Meghalaya, pp. 10-11. In: Proc. Nat. Sem. Explo. Conserv. Therap. Imp. Medi. Plants in North East India.

Sharma, A. (2012): Traditional processing of Shotti (Curcuma angustifolia Roxb.) A rhizome-based ethnic weaning food. India. J. Trad. Knowl., 11(1):154-155.

Sharma, N., Chandel, M. \& Sharma, N. (2021): Studies on traditional Indian (Turmeric) pickle as a probiotic pickle for therapeutic uses in view of COVID-19 pandemic. India. J. Tradit. Knowl., 19:S-143.

Sikha, A. \& Harini, A. (2015): Pharmacological activities of wild turmeric (Curcuma aromatica Salisb): A Rev. J. Pharmacogn. Phytochem., 3(5):01-04.

Sirirugsa, P., Larsen, K. \& Maknoi, C. (2007): The genus Curcuma L. (Zingiberaceae): distribution and classification with reference to species diversity in Thailand. Gardens Bull. Singapore, 59:203-220.

Srivastava, A.K., Srivastava, S.K. \& Syamsundar, K.V. (2006): Volatile composition of Curcuma angustifolia Roxb. rhizome from central and southern India. Flavour Fragr. I., 21(3):423426.

Tanvir, E.M., Hossen, M., Hossain, M., Afroz, R., Gan, S.H., Khalil, M. \& Karim, N. (2017): Antioxidant properties of popular 
turmeric (Curcuma longa) varieties from Bangladesh. J. Food Quality., 8471785:8.

Tiwari, N.K., Gurjar, P.S., Pandey, A.K. \& Singh, U.N. (2018): Studies on varietal performance of growth and yield attributing trade-in turmeric (Curcuma longa L.). I. Pharmacogn. Phytochem., 7(5):861-863.

Varma, K. \& Gopi, S. (2020): Production, economics, and marketing of turmeric, pp. 307-323. In: The Chemistry and Bioactive Components of Turmeric. Pub. by: Royal Society of Chemistry,

Velayudhan, K.C., Dikshit, N. \& Nizar, M.A. (2012): Ethnobotany of turmeric (Curcuma longa L.). India. J. Tradit. Knowl., $11(4): 607-614$.
Verma, R.K., Kumari, P., Maurya, R.K., Kumar, V., Verma, R.B. \& Singh, R.K. (2018): Medicinal properties of turmeric (Curcuma longa L.): a review. Int. J. Chem. Stud., 6(4):13541357.

Yadav, R.P., Tarun, G., Roshan, C. \& Yadav, P. (2017): Versatility of turmeric: A review of the golden spice of life.J. Pharm. Pharmacol.,6(1):41-46.

Zdrojewicz, Z., Szyca, M., Popowicz, E., Michalik, T. \& Smieszniak, B. (2017): Turmeric-not only spice. Polski Merkuriusz Lekarski: Organ Polskiego Towarzystwa Lekarskiego., 42(252):227-230. 